\title{
Características morfológicas e fitossanitárias de variedades de roseira na etapa de classificação
}

\author{
Morphological and fitossanitary characteristics in rose varieties on classification stage
}

\author{
Beatriz Meireles Barguil ${ }^{\mathrm{I}}$ Francisco Marto Pinto VianaII José Luiz Mosca ${ }^{\text {II }}$
}

\section{RESUMO}

A qualidade da haste floral de roseira é afetada por inúmeros defeitos, como botão pequeno ou presença de doenças e ferimentos. Este trabalho teve como objetivo avaliar as características morfológicas (comprimento e retidão da haste e do botão floral) e fitossanitárias (incidência de míldio, oídio, mofo cinzento e dano causado por lagarta) de sete variedades de roseira cultivadas em ambiente protegido. As características foram observadas em três avaliações. O comprimento médio de haste floral variou de 56,1 a $83,3 \mathrm{~cm}$, enquanto que o comprimento médio dos botões variou de 4,7 a 5,2cm. Foram observados sintomas de míldio, oídio, mofo cinzento e injúria causada por lagarta nas hastes florais, sendo o oídio o principal problema fitossanitário observado, tendo afetado de 2,9 a 41,3\% das hastes, dependendo da variedade. Cerca de $70 \%$ das hastes de cada variedade apresentaram características do tipo de C ou D durante a etapa de classificação. Esses resultados reforçam a necessidade da avaliação das diversas características das variedades adquiridas, antes da implementação do cultivo comercial.

Palavras-chave: classificação da haste, comprimento do botão, comprimento da haste, doenças fúngicas, Rosa sp.

\section{ABSTRACT}

The quality of the rose's floral stem can be affected by numerous faults as small button or diseases and injuries. This study aimed to evaluate the morphological (length and rightness of stem and rose bud) and fitossanitary (downy mildew, powdery mildew, gray mold and caterpillar damage) characteristics in seven varieties of rose grown in a greenhouse. The characteristics were analyzed three times. The average length of floral stems ranged from 56.1 to $83.3 \mathrm{~cm}$, while the average length of buttons ranged from 4.7 to $5.2 \mathrm{~cm}$ in the varieties evaluated. Symptoms of downy mildew, powdery mildew, gray mold and damage caused by caterpillar were observed, although powdery mildew were the main problem witch affect from 2,9 to $41,3 \%$ of floral stems. About $70 \%$ of the stems of all varieties showed characteristics of type $C$ or $D$ during the classification stage. These results reinforce the necessity of evaluating new varieties before the implementation of commercial cultivation.

Key words: bud length, fungi diseases, stem classification, stem length, Rosa sp.

\section{INTRODUÇÃO}

A roseira é a espécie ornamental mais conhecida em todo o mundo e sua haste floral encontrase entre as flores mais admiradas, pela sua beleza e simbologia. A rosa (Rosa spp.) é a principal flor de corte exportada pelo Brasil e também a mais procurada no mercado interno. A partir do ano 2000, o Estado do Ceará iniciou o cultivo protegido de rosas, ocupando já em 2007 a posição de principal exportador brasileiro de rosas (JUNQUEIRA \& PEETZ, 2009).

De acordo com REICH \& CARVALHO (2004), a coloração do botão floral com maior demanda de mercado é a vermelha, sendo procurada por $29 \%$ dos consumidores, enquanto aquelas com coloração champanhe, rosa e amarela ficaram com 20, 17 e 16\% da preferência do consumidor, respectivamente. Na cidade

'Fundação Cearense de Apoio ao Desenvolvimento Científico e Tecnológico (FUNCAP), 60511-110, Fortaleza, CE, Brasil. Email: beatriz_barguil@hotmail.com. Autor para correspondência.

"Embrapa Agroindústria Tropical (CNPAT), Fortaleza, CE, Brasil. 
de Curitiba- PR, o produto mais procurado nas floriculturas foi o buquê de rosas (38\%), seguido por outras flores em buquê (18\%), flores em vaso (15\%), arranjos (15\%), plantas para jardim (11\%) e mudas (3\%) (LARA\& CARVALHO, 2003).

Na maioria das regiões produtoras de rosas, ocorrem diversos problemas fitossanitários, destacando-se as doenças de etiologia fúngica na parte aérea, como o míldio, o oídio e o mofo cinzento (HORST, 1998). Os sintomas de míldio (Peronospora sparsa Berk), oídio (Sphaerotheca pannosa (Wallr. Ex Fr.) Lev.) e mofo cinzento (Botrytis cinerea Pers. Fr.) podem ser observados sobre as hastes, folhas e pétalas. Entretanto, o principal dano do míldio e do oídio ocorre sobre a capacidade fotossintética da planta, pelo fato de favorecerem a senescência e a deformação foliar, respectivamente, enquanto o mofo cinzento se desenvolve principalmente sobre o botão floral, prejudicando a sua comercialização (HORST, 1998). Portanto, essas doenças comprometem tanto a quantidade, quanto a qualidade da produção de hastes florais.

As pragas mais comuns em roseira são os ácaros, os pulgões, os tripes e as lagartas, que podem atacar folhas e botões florais. Além de causarem danos às plantas, algumas espécies de tripes e de pulgões também podem transmitir viroses (BARBOSA, 2003). Durante a classificação, até duas hastes pouco danificadas por insetos são permitidas por maço (COOPERATIVA VEILING HOLAMBRA, 2009).

Na etapa de classificação de hastes florais de roseira, são observadas características importantes, como o comprimento da haste e do botão, a espessura da haste e o ponto de abertura do botão. A ausência de defeitos graves, como danos causados por doenças e pragas e danos mecânicos nas folhas e na flor, é recomendada para uma haste de qualidade, pois esses defeitos podem evoluir durante o processo de comercialização (COOPERATIVA VEILING HOLAMBRA, 2009).

Em razão da falta de dados sobre as principais características em hastes florais de roseira, inclusive sobre os defeitos de origem fitossanitária, idealizou-se este trabalho com o objetivo de avaliar as características morfológicas e fitossanitárias em sete variedades de roseira cultivadas em ambiente protegido e verificar quais as características que comprometem a qualidade dessa importante cultura para o Estado do Ceará.

\section{MATERIAL E MÉTODOS}

Roseiras foram cultivadas em estufa localizada no município de São Benedito - CE com a finalidade de verificar as características fenotípicas de diferentes variedades. Esse município situa-se na Chapada da Ibiapaba, região noroeste do Estado do Ceará, distante $330 \mathrm{~km}$ da capital (latitude: $4^{\circ} 02^{\prime} \mathrm{S}$, longitude: $40^{\circ} 51^{\prime} \mathrm{W}$, altitude: $900 \mathrm{~m}$ ).

As hastes florais utilizadas no experimento foram colhidas de plantas com dois a três anos de idade, cultivadas em fileiras duplas e fertirrigadas por gotejamento. Durante o experimento, as plantas foram pulverizadas com defensivos a cada 10 dias, para o manejo de oídio e de ácaro.

Foram avaliadas sete variedades de roseira com distinta coloração de botão: Ambiance (amarela com borda cor de rosa), Avalanche (branca), Carola (vermelha), Elisa (rosa), Gold Strike (amarela), Salmone (salmão) e Tresor 2000 (alaranjada). As quantidades de hastes analisadas se basearam na preferência do consumidor, uma vez que rosas vermelhas são mais comercializadas que as demais. Assim, em cada avaliação, foram observadas 500 hastes florais de Carola, 300 de Avalanche e 150 hastes de cada uma das demais variedades. As características morfológicas observadas foram: comprimento da haste, que compreendeu a medida da base da haste até a ponta do botão; comprimento do botão floral, que compreendeu a medida da base da pétala até a ponta do botão; haste reta e botão floral reto. Também foi avaliada a incidência de hastes com os seguintes problemas fitossanitários: míldio, oídio, mofo cinzento e injúria causada por lagarta.

As hastes foram classificadas com base nos seguintes caracteres morfológicos:

Tipo A: haste reta, botão reto e haste com no mínimo $60 \mathrm{~cm}$ de comprimento;

Tipo B: haste pouco torta ou botão pouco torto e haste com no mínimo 60cm de comprimento;

Tipo C: haste pouco torta ou botão pouco torto e haste com no mínimo 50cm de comprimento;

Tipo D: haste pouco torta ou botão pouco torto e haste com no mínimo 40cm de comprimento;

Tipo E: haste torta e/ou botão torto e haste com no mínimo 40cm de comprimento.

As características das sete variedades foram avaliadas nos meses de julho, setembro e novembro de 2008. Foram calculados os percentuais de hastes florais retas, com botão reto, e a incidência de hastes com sintomas de míldio, oídio e mofo cinzento e com injúria causada por lagarta. Também foram obtidos os percentuais de hastes florais para cada tipo de classificação. Após a obtenção dos valores em cada 
mês de avaliação, os dados foram submetidos à análise de variância, e as médias foram separadas pelo teste de Tukey, a 5\% de probabilidade, com auxílio do programa SAEG. Os dados de incidência de míldio, oídio e dano causado por lagarta foram transformados em $\sqrt{(x+0,5)}$.

\section{RESULTADOS E DISCUSSÃO}

O comprimento de haste e do botão mudou de acordo com a variedade analisada (Tabela 1). As variedades Carola e Salmone produziram hastes mais compridas que as demais variedades, com valores de 82,77 e $80,52 \mathrm{~cm}$, respectivamente. As variedades Ambiance, Avalanche e Gold Strike produziram as menores hastes, com valores entre 56 e $63 \mathrm{~cm}$ de comprimento, tendo diferido das demais. O comprimento da haste de Ambiance $(56,16 \mathrm{~cm})$ foi inferior ao observado por VILLAS BÔAS et al. (2008), que relataram média de $68,6 \mathrm{~cm}$. Entretanto, o oposto ocorreu com hastes de Carola $(83,3 \mathrm{~cm})$, em que esses autores observaram valores médios menores. O comprimento da haste é a primeira característica a ser observada durante a classificação da haste floral de roseira, sendo as hastes com comprimento entre 60 e $90 \mathrm{~cm}$ as mais valorizadas.

O menor comprimento de botão foi observado na variedade Gold Strike, com 4,69cm, enquanto os maiores valores ocorreram nas variedades Carola e Elisa, com 5,16 e 5,26cm, respectivamente, que diferiram das demais variedades (Tabela 1). Valores maiores de comprimento de haste e de botão propiciam melhor classificação da haste, favorecendo o lucro do produtor.

Embora as médias de percentuais de hastes retas tenham apresentado normalidade e homogeneidade, a análise de variância foi não significativa. É importante ressaltar que, nas variedades
Ambiance, Avalanche, Elisa e Tresor 2000, esses percentuais ficaram compreendidos entre 81,6 e 88,7\% (Tabela 1). Essa característica mostrou-se importante para a estética e também para facilitar a embalagem das hastes nas caixas para o transporte.

As médias dos percentuais de botões retos também não foram significativas após a análise, embora tenham apresentado normalidade e homogeneidade. Na variedade Avalanche, foi observado que a média das avaliações alcançou o valor de 96,7\% para essa característica (Tabela 1). O comprimento entre a última folha e a base do botão, em hastes da Carola, foi superior a $10 \mathrm{~cm}$. Essa característica da variedade pode favorecer que o botão fique torto ou que essa região da haste entorte devido ao peso do botão, o que pode diminuir o valor comercial da haste ou torná-la imprópria para o comércio.

Todas as variedades analisadas apresentaram sintomas de míldio durante o período do experimento, com exceção da variedade Ambiance (Tabela 2). Na variedade Elisa, foi observado o maior percentual de hastes sintomáticas $(9,3 \%)$, que diferiu significativamente das variedades Salmone e Ambiance.

Apesar das pulverizações periódicas realizadas durante o experimento, os sintomas de oídio foram observados em todas as variedades avaliadas. A incidência dessa doença foi maior na segunda e na terceira avaliação, provavelmente, em razão da presença de condições ambientais favoráveis ao desenvolvimento do patógeno e da doença, como temperatura diurna acima dos $24^{\circ} \mathrm{C}$. Outros fatores que podem ter contribuído para o aumento do número de hastes com sintoma de oídio foram a frequência e intensidade dos ventos nessa época do ano, na região do cultivo, que auxiliam na disseminação dos esporos do patógeno (HORST, 1998). Em razão da ampla

Tabela 1 - Comprimento médio de haste e do botão e percentuais de hastes e botões retos em variedades de roseira.

\begin{tabular}{|c|c|c|c|c|}
\hline Variedade & $\begin{array}{l}\text { Comprimento de haste } \\
\text { (cm) }\end{array}$ & $\begin{array}{l}\text { Comprimento de botão } \\
\qquad(\mathrm{cm})\end{array}$ & Haste reta (\%) & Botão reto (\%) \\
\hline Ambiance & $56,16 f^{*}$ & $5,10 \mathrm{c}$ & $88,7^{\mathrm{NS}}$ & $79,6^{\mathrm{NS}}$ \\
\hline Avalanche & $62,46 \mathrm{e}$ & $4,84 \mathrm{~d}$ & 84,5 & 96,7 \\
\hline Carola & $82,77 \mathrm{a}$ & $5,16 \mathrm{~b}$ & 68,9 & 77,2 \\
\hline Elisa & 76,68 с & 5,26 a & 87,0 & 80,3 \\
\hline Gold Strike & $62,71 \mathrm{e}$ & 4,69 e & 73,2 & 86,5 \\
\hline Salmone & 80,52 b & $4,87 \mathrm{~d}$ & 76,7 & 86,3 \\
\hline Tresor 2000 & $66,66 \mathrm{~d}$ & $4,82 \mathrm{~d}$ & 81,6 & 85,6 \\
\hline $\mathrm{CV} \%$ & 4,99 & 3,87 & 14,21 & 15,21 \\
\hline
\end{tabular}

Ns: Não significativo. * Médias seguidas por letras distintas diferem entre si pelo teste de Tukey, a 5\% de probabilidade. 
Tabela 2 - Incidência de míldio, oídio e injúria causada por lagarta em hastes de variedades de roseira.

\begin{tabular}{lclc}
\hline Variedade & Míldio (\%) & Oídio (\%) & $\begin{array}{c}\text { Injúria por lagarta } \\
\text { (\%) }\end{array}$ \\
\hline Ambiance & $0,0 \mathrm{~b}^{*}$ & $29,9^{\mathrm{NS}}$ & $0,0^{\mathrm{NS}}$ \\
Avalanche & $6,4 \mathrm{ab}$ & 6,8 & 0,0 \\
Carola & $3,6 \mathrm{ab}$ & 13,3 & 0,4 \\
Elisa & $9,3 \mathrm{a}$ & 2,4 & 0,4 \\
Gold Strike & $2,4 \mathrm{ab}$ & 9,9 & 0,0 \\
Salmone & $0,8 \mathrm{~b}$ & 31,5 & 0,7 \\
Tresor 2000 & $2,6 \mathrm{ab}$ & 41,3 & 0,4 \\
CV(\%) & 37,31 & 65,06 & 3,48 \\
\hline
\end{tabular}

Ns: Não significativo. *Médias seguidas por letras distintas diferem entre si pelo teste de Tukey, a 5\% de probabilidade.

variação dos valores de incidência entre as três avaliações realizadas, os dados foram não significativos na análise de variância. Nas variedades Ambiance, Salmone e Tresor 2000, foram obtidas médias compreendidas entre 29 e 42\% de incidência da doença nas hastes florais (Tabela 2).

Os sintomas de mofo cinzento foram observados em 2,0 e 0,6\% das hastes das variedades Avalanche e Tresor, respectivamente, mas apenas na primeira avaliação, que foi realizada no mês de julho. A ausência de sintomas na segunda e na terceira avaliação pode ser explicada pela mudança nas condições ambientais durante os últimos quatro meses do ano na região onde o experimento foi conduzido, que se tornaram desfavoráveis à ocorrência da doença. Outro fator que pode explicar a baixa incidência dessa doença durante o experimento é que o patógeno, após penetrar no tecido do hospedeiro, pode permanecer latente, e os sintomas se tornarem visíveis apenas na presença de condições ambientais favoráveis, que ocorrem mais frequentemente nas fases de armazenamento, transporte e comercialização dos maços, conforme mencionado por HORST (1998).

Entre as principais pragas que podem prejudicar a produção de hastes de roseira de qualidade, destacam-se as lagartas. Danos causados por lagartas do gênero Spodoptera foram observados em botões das variedades Carola, Elisa, Salmone e Tresor 2000 (Tabela 2). Embora as médias desses percentuais tenham sido inferiores a 1,0\%, é importante ressaltar que hastes florais apresentando injúria causada por lagarta no botão ou na haste geralmente são descartadas, por serem inviáveis ao comércio.

As variedades Carola, Elisa, Salmone e Tresor 2000 não diferiram entre si em relação ao percentual de haste tipo B, mas diferiram de Ambiance, em que apenas $0,86 \%$ das hastes receberam essa classificação. Hastes florais de roseira com padrão tipo $\mathrm{C}$ e D foram as mais frequentes, não diferindo entre si em todas as variedades avaliadas (Tabela 3 ). Os padrões de classificação tipo B e E não diferiram entre si em todas as variedades avaliadas e representam os menores percentuais na classificação das hastes.

A qualidade final da haste é alterada se sintomas de doenças ou de pragas forem visíveis, resultando na diminuição do valor comercial da haste ou até mesmo na sua desqualificação para a comercialização (COOPERATIVA VEILING HOLAMBRA, 2009). Dessa maneira, é importante o manejo adequado das doenças na cultura da roseira durante todo o ciclo de crescimento da haste floral, para assegurar a qualidade da produção.

Observou-se que as variedades Carola, Elisa e Salmone apresentaram comprimento médio de haste superior a $71 \mathrm{~cm}$, evidenciando o potencial genético dessas variedades. Entretanto, os percentuais de hastes tipo A dessas variedades foram aquém do esperado, tendo sido obtidas, com maior frequência, hastes tipo C e D. Nessas variedades, a soma dos percentuais de hastes C e D foi de 76,2; 76,5 e 63,7\%, respectivamente. Tal diferença entre o tamanho da haste colhida e o comprimento após a classificação deve-se, em parte, à existência de hastes tortas, cujo comprimento é reduzido pelo corte efetuado durante a classificação da haste, objetivando a obtenção de um produto de qualidade.

As variedades Ambiance, Avalanche, Gold Strike e Tresor 2000 apresentaram hastes de tamanho médio de $60 \mathrm{~cm}$ e botões também com classificação de tamanho médio. Hastes e botões retos foram observados em mais de 79\% das hastes de "Ambiance”, “Avalanche” e "Tresor 2000"; entretanto, na variedade Gold Strike, o percentual de hastes retas foi de 73,2\%. Essas características tornam interessante o cultivo dessas variedades, pois atendem às exigências do mercado interno.

As variedades Carola, Elisa e Salmone apresentaram hastes longas $(>76 \mathrm{~cm})$ e botões de tamanho médio de $5,0 \mathrm{~cm}$, tornado-as apropriadas também para a exportação. Porém, a variedade Carola apresentou percentuais de hastes e de botões retos inferiores a 78\%, comprometendo a classificação das hastes dentro do padrão de qualidade.

Em razão das condições ambientais favoráveis, as variedades Ambiance, Salmone e Tresor 2000 apresentaram suscetibilidade ao agente causal do oídio, com incidência média acima de 29\%. As variedades Avalanche e Elisa apresentaram maior incidência de hastes com sintomas de míldio, durante o período de avaliação. O cultivo de variedades 
Tabela 3 - Percentuais dos tipos de haste analisadas de sete variedades de roseira, segundo a classificação proposta neste trabalho.

\begin{tabular}{|c|c|c|c|c|c|c|}
\hline & Tipo A (\%) & Tipo B (\%) & Tipo C (\%) & Tipo D (\%) & Tipo E (\%) & CV (\%) \\
\hline Ambiance & 16,87 bc* & $0,86 \mathrm{cB}$ & $35,30 \mathrm{ab}$ & 45,96 a & $1,70 \mathrm{c}$ & 41,5 \\
\hline Avalanche & $13,08 \mathrm{~b}$ & 1,65 сAB & 39,54 a & 44,32 a & $1,76 \mathrm{c}$ & 14,3 \\
\hline Carola & $8,86 \mathrm{~b}$ & $8,13 \mathrm{bA}$ & $33,80 \mathrm{a}$ & $42,40 \mathrm{a}$ & $6,53 \mathrm{~b}$ & 32,5 \\
\hline Elisa & $11,55 \mathrm{~b}$ & 8,86 bA & 37,33 a & 39,30 a & $3,10 \mathrm{~b}$ & 18,3 \\
\hline Gold Strike & $16,44 \mathrm{~b}$ & 6,87bcAB & $39,75 \mathrm{a}$ & $34,88 \mathrm{a}$ & $1,99 \mathrm{c}$ & 18,7 \\
\hline Salmone & $22,21 \mathrm{ab}$ & 8,87 bA & 29,32 a & 34,42 a & $4,87 \mathrm{~b}$ & 33,8 \\
\hline Tresor & $18,44 \mathrm{ab}$ & $8,44 \mathrm{bA}$ & 37,11 a & 33,32 a & $2,66 \mathrm{~b}$ & 38,9 \\
\hline CV(\%) & - & 40,9 & - & - & - & \\
\hline
\end{tabular}

*Médias seguidas pela por letras distintas, minúscula na linha ou maiúscula na coluna, diferem entre si pelo teste de Tukey, a 5\% de probabilidade.

suscetíveis pode acarretar aumento no custo de produção e, em alguns casos, tornar o cultivo inviável.

Esses resultados demonstram a necessidade de o produtor avaliar as características morfológicas e a suscetibilidade a pragas e doenças de novas variedades, antes de implementar o cultivo comercial, pois a expressão de diversas características fenotípicas em roseira pode ser influenciada pela temperatura (BARBOSA, 2003), duração do dia (ALMENAIE \&AL-SHATTI, 2008), irrigação(FOLEGATTI et al., 2001) e nutrição (BARBOSA et al., 2007).

\section{AGRADECIMENTOS}

Os autores agradecem ao convênio CNPq/FUNCAP, pela concessão de bolsa DCR.

\section{REFERÊNCIAS}

AL-MENAIE, H.S.; AL-SHATTI, A.A. Impact of seasonal variation on rose flower production under greenhouse conditions in Kuwait. Journal of Food, Agriculture \& Environment, v.6, n.2, p.378-380, 2008. Disponível em: <http://www.worldfood.net/scientficjournal/2008/issue2.php>. Acesso em: 24 fev. 2009.

BARBOSA, J.G. Produção comercial de rosas. Viçosa: Aprenda Fácil, 2003. 200p.

BARBOSA, J.G. et al. Quality and commercial grade of rose yields as affected by potassium applications through drip irrigation. Acta Horticulture, v.751, p.83-87, 2007. Disponível em: $<$ http://www.actahort.org/books/751/751_8.htm>. Acesso em: 30 mar. 2009.

COOPERATIVA VEILING HOLAMBRA. Critério de classificação de rosa de corte. 8p. Disponível em: <http:/ /www.ibraflor.org/ sis.interna.asp?pasta=1\&pagina=88>. Acesso em: 10 jan. 2009.

FOLEGATTI, M.V. et al. Greenhouse irrigation water depths in relation to rose stem and bud qualities. Scientia Agricola, v.58, n.3, p.465-468, 2001. Disponível em: <http:// www.scielo.br/ pdf/sa/v58n3/a04v58n3.pdf >. Acesso em: 10 jan. 2009. doi: 10.1590/S0103-90162001000300004.

HORST, R.K. Compendio de enfermidades de rosas. Quito: Gráficas Universal, 1998. 50p.

JUNQUEIRA, A.H.; PEETZ, M.S. Exportações de flores e plantas ornamentais superam US\$ 35 milhões em 2007: recorde e novos desafios para o Brasil. Disponível em: <http://www.hortica.com.br>. Acesso em: 20 fev. 2009.

LARA, A.P.C.; CARVALHO, R.I.N. Perfil dos comerciantes e consumidores de plantas ornamentais em Curitiba-PR. Revista Acadêmica: ciências agrárias e ambientais, v.1, n.3, p.5558, 2003. Disponível em: <http://www2.pucpr.br/reol/ index.php/ACADEMICA?dd1= 77>. Acesso em: 20 jan. 2009.

REICH, F.S.; CARVALHO, R.I.N. Comercialização de rosas, violetas e crisântemos em Curitiba-PR. Revista Acadêmica: ciências agrárias e ambientais, v.2, n.3, p.19-26, 2004. Disponível em: <http://www2.pucpr.br/reol/index.php/ACADEMICA?dd1=80 >. Acesso em: 20 jan. 2009.

SEBRAE AGRONEGÓCIOS. Serviço brasileiro de apoio às micro e pequenas empresas. Brasília: Gráfica Ipiranga, 2005. N.1.

VILLAS BÔAS, R.L. et al. Exportação de nutrientes e qualidade de cultivares de rosas em campo e em ambiente protegido. Horticultura Brasileira, v.26, n.4, p.515-519, 2008. Disponível em: <http:// www.scielo.br/scielo.php?script=sci_arttext\&pid=S0102-0536200 8000400018\&lng=pt\&nrm=iso $>$. Acesso em: 20 fev. 2009. doi: 10.1590/S0102-05362008000400018. 